3. Распоряжение Правительства РФ от 29 мая 2015 г. № 996-р «Об утверждении Стратегии развития воспитания в Российской Федерации на период до 2025 года» // Официальный интернет-портал правовой информации http://www.pravo.gov.ru, 02.06.2015.

4. Закон Московской области от 27 июля 2013 г. № 94/2013-О3 «Об образовании» (принят постановлением Мособлдумы от 11 июля 2013 г. № 17/59-П) // Ежедневные Новости. Подмосковье. - 2013. - № 144.

5. Гидденс Э., Саттон Ф. Основные понятия в социологии / пер. с англ. Е. Рождественской, С. Гавриленко; под науч. ред. С. Гавриленко; Нац. исслед. ун-т «Высшая школа экономики» - 2-е изд. - М.: Изд. дом. Высшей школы экономики, 2019. - 336 с.

6. Коджаспирова Г.М., Коджаспиров А.Ю. Словарь по педагогике. - М.: ИКЦ «МарТ»; Ростов н/Д: Издательский центр «МарТ», 2005. - 448 с.

7. Научные концепции развития российского законодательства: монография. 7-е изд. доп. и перераб. /С.Е. Нарышкин, Т.Я. Хабриева, А.И. Абрамова и др.; отв. Ред. Т.Я. Хабриева, Ю.А. Тихомиров; Институт законодательства и сравнительного правоведения при Правительстве Российской Федерации. - М.: ИД Юриспруденция, 2015. - 544 с.

8. Образовательное законодательство России. Новая веха развития: монография / Л.В. Андриченко, В.Л. Баранков, Б.А. Булаевский и др.; отв. ред. Н.В. Путило, Н.С. Волкова; Институт законодательства и сравнительного правоведения при Правительстве Российской Федерации. М.: ИД Юриспруденция, 2015. - 480 с.

9. Педагогика и психология: учебник для бакалавров/под ред. П.И. Пидкасистого. - 3-е изд. перераб. и доп. - М.: Издательство Юрайт; ИД Юрайт, 2012. - 724 с.

10. Педагогика физической культуры и спорта: проблемы и перспективы: коллективная монография / отв. ред. А.Ю. Нагорнова. - Ульяновск: Зебра, 2020. - 208 с.

11. Подласый И.П. Педагогика: учебник для бакалавров/И.П. Подласый. - 2-е изд., перераб. и доп. М.: Издательство Юрайт; ИД Юрайт, 2012. - 574 с.

12. Правовая политика в сфере образования: словарь / под ред. А.В. Малько и Д.А. Смирнова. Москва: Проспект, 2017. - 160 с.

13. Сластенин В.А. Педагогика: учебник для студ. учреждений высш. проф. образования /В.А. Сластенин, И.Ф. Исаев, Е.Н. Шиянов; под ред. В.А. Сластенина. - 10-е изд., перераб. - М.: Издательский центр «Академия», 2011. - 608 с.

14. Словарь по социальной педагогике: Учебное пособие для студ. высш. учеб. заведений / Авт.-сост. Л.В. Мардахаев. - М.: Издательский центр «Академия», 2002. - 368 с.

15. Тенчурина Л.З., Удалов Д.Э., Удалова А.Э. Педагогические и правовые основы гражданскопатриотического воспитания (в аспекте подготовки кадров для туризма) // Научное обозрение: гуманитарные исследования. 2016. № 10. С. 23-31.

16. Удалова А.Э., Удалов Д.Э. Вопросы законодательного регулирования профессиональной деятельности в области физической культуры и спорта // Тенденции развития науки и образования. 2021. № 70-5. С. 55-58.

\title{
Федоров Г.М. \\ Модульный курс «ОБЖ - кочевье» для детей коренных малочисленных народов Севера, Сибири и Дальнего Востока Российской Федерации
}

ФГБУ «Федеральный институт родных языков народов Российской Федераичии»

(Россия, Москва)

doi: 10.18411/lj-06-2021-190

\section{Аннотация}

Статья посвящена решению методических проблем, связанных с определением методического основания и разработкой модульного курса «ОБЖ - кочевье» по образовательной области «Окружающий мир» в начальных кочевых школах коренных малочисленных народов Севера, Сибири и Дальнего Востока Российской Федерации.

Обосновано научное основание курса «ОБЖ - кочевье» для 1-4 ориентированное на сочетание теоретического и практического компонентов образовательных программ в отношении безопасности кочевого образа жизни. Такой деятельности главной выступает формирование новых привычек по безопасности жизни, приобретение навыков безопасного поведения, здорового образа жизни в условиях кочевья. 
Ключевые слова: кочевье, коренных малочисленные народы, ОБЖ, начальная кочевая школа, обучающиеся начальных классов, модульный курс, учебное пособие, образовательная программа, окружающий мир, здоровье, ЗОЖ, безопасное поведение в местах кочевья.

\section{Abstract}

The article is devoted to the solution of methodological problems associated with the determination of the methodological basis and the development of a modular course "Life Safety - nomad territory" in the educational area "Surrounding world" in primary nomadic schools of the indigenous small-numbered peoples of the North, Siberia and the Far East of the Russian Federation.

The scientific basis of the "Life safety - nomad territory" course for grades 1-4 focused on the combination of theoretical and practical components of educational programs concerning the safety of a nomadic way of life has been substantiated. The main activity is the formation of new habits for the safety of life, the acquisition of skills for safe behavior, and a healthy lifestyle in nomadic conditions.

Keywords: nomad territory, indigenous small-numbered peoples, life safety, primary nomadic school, primary school students, modular course, textbook, educational program, surrounding world, health, healthy lifestyle, safe behavior in places of nomad territory.

В настоящее время безопасное поведение, позитивное здоровое отношение к бытию, формирование культуры безопасности жизни у детей приобретает особую актуальность.

В начальной школе в соответствии целями, задачами и требованиями ФГОС начального общего образования не предусматривает изучение предмета «Основы безопасности жизнедеятельности» (далее - ОБЖ) как отдельный предмет.

Особенностью преподавания ОБЖ в начальной школе является то, что предмет ОБЖ изучается на уроках по предмету «Окружающий мир». Содержание ОБЖ по образовательной области «Окружающий мир» определены стандартом начального общего образования. Все действующие вариативные курсы, реализующие содержание предмета «Окружающий мир» для 1-4 классов в основном включают содержание программ и учебников по основам безопасной жизни детей в различных непредвиденных, опасных ситуациях городской среды. В начальной школе для расширения содержания ОБЖ разработаны и используются в образовательный процесс учебники «ОБЖ» (А.В. Гостюшин, А.А. Усачев, А.И. Березин).

Как показывают вариативность подходов к изучению ОБЖ значительно обогащает теорию и практику обучения безопасности жизни у обучающихся младших классов.

Несомненный интерес представляет позиция В.В. Гафнера о том, что как «формируется у ребенка отношение к личной безопасности и закладывается отношение к безопасности общества, в котором он живет» [1]. Вместе с тем, мнение В.В. Гафнера о «недостаточном внимании по вопросам безопасности в начальной школе становится препятствием для формирования полноценной культуры безопасности у учащихся в старшем звене» [1] говорить о необходимости и целесообразности разработки и использование вариативных программ, курсов по основам безопасности жизни детей в начальной школе.

Особую значимость и ценность решение этой проблемы представляет Концепция преподавания учебного предмета «Основы безопасности жизнедеятельности» (далее - Концепция) в образовательных организациях, реализующих основные общеобразовательные программы ФГОС общего образования.

В этой концепции определены значение предмета «ОБЖ» в системе общего образования. Выявлены проблемы изучения и преподавания предмета «ОБЖ», 
связанные с вопросами безопасности личности, общества и государства, которые объединяют проблемы мотивации, содержание и методики обучения. В данной концепции определены способы и механизмы их реализации. Это, во-первых, решение проблемы мотивации, т.е. интереса детей к изучению данного предмета, которая больше всего связана с использованием на уроках «вариативных практикоориентированных методов обучения» [5]. Во-вторых, проблема содержание курса ОБЖ «с минимальным объемом необходимых знаний по вопросам безопасности обучающихся, соответствующих их возрасту и уровню образования» [4]. В-третьих, совершенствование методики обучения, в котором непременно «реализовать тематическое планирование в соответствии принципу последовательного усложнения и закрепления знаний по ОБЖ» [4].

Указанные в Концепции проблемы мотивационного, содержательного и методического характера нам представляются актуальными и способствуют «формированию модели безопасного поведения детей, в особенности младшего школьного возраста, в условиях повседневной жизни и в различных опасных и чрезвычайных ситуациях» [4].

Для реализации данной Концепции в образовательных организациях Российской Федерации, реализующих основные общеобразовательные программы на 2020-2024 гг. Министерство просвещения Российской Федерации утвердил план мероприятий в том числе «разработки рекомендаций по корректировке действующих и созданию новых учебно-методических комплектов по учебным предметам «Окружающий мир» (в отношении вопросов безопасности) и «Основы безопасности жизнедеятельности (в отношении дифференциации и индивидуализации обучения, ориентированных на сочетание теоретического и практического (приоритетного) компонентов образовательных программ)» [4].

Вышеперечисленные факторы, обстоятельства позволили определить методологические основания к разработке модульного курса «ОБЖ - кочевье» по предмету «Окружающий мир» для 1-4 классов в формате программы и учебных пособий с учетом природно-климатических, социо-природных условий, факторов кочевой жизни, возрастных и индивидуальных особенностей обучающихся младших классов.

В этой связи за научную основу модульного курса «ОБЖ - кочевье» выступают деятельностный подход, дифференциации и индивидуализации обучения.

Деятельностный подход является методологическим основанием в части содержания и методики обучения модульного курса «ОБЖ - кочевье». Освоение новых умений и навыков невозможно без практической деятельности. Особенностью обучения по данному курсу является совместная деятельность детей, нахождение способов действий, операций, алгоритмов из создавшейся опасных ситуации, приобретение ими первоначальных навыков безопасного поведения, культуры здорового и безопасного образа жизни, здорового образа жизни, сохранение здоровья.

Первостепенное значение представляет практическая, проектная, творческая, исследовательская деятельность, результатом которой является определенный продукт как безопасное поведение детей до кочевки, во время кочевки, и после кочевки, участвовать в утеплении жилья, устилать ивовыми прутьями, а поверх плетеные коврики из растений (циновки), доски и шкурами оленей - спальные места, помочь обкладывании камнями покрышку яранги или чума, чтобы не сдуло во время сильного ветра или пурги и т.д.

В ходе такой деятельности происходит выработка индивидуальной образовательной траектории, что важно в кочевых условиях при составлении маршрутов кочевья, формировании новых привычек по безопасности кочевой жизни. При этом открываются возможности личностного роста детей в части безопасного поведения в местах кочевья, мобилизация в экстремальных жизненных условиях, 
осуществление деятельности без посторонней помощи в экстремальных ситуациях, самосовершенствование культуры здоровой и безопасной жизни.

Таким образом, планируемыми результатами деятельности модульного курса «ОБЖ - кочевье» могут быть приобретение навыков безопасности, безопасного поведения, культуры здоровой жизни детей в общине, в стойбище, в жилище, в природе в условиях кочевья.

$$
* * *
$$

1. Гафнер В. В. Предмет ОБЖ в свете ФГОС общего образования второго поколения // Вестник НЦБЖД, №4 (18), с. 32-38

2. Концепция преподавания учебного предмета «Основы безопасности жизнедеятельности» в образовательных организациях Российской Федерации, реализующих основные общеобразовательные программы (mosmetod.ru)

3. https://docs.edu.gov.ru/document/bac5f1cd420a477b847e931322e90762

4. Приказ Министерства образования и науки Российской Федерации №373 от 6 октября 2009 г. «Об утверждении и введении в действие федерального государственного образовательного стандарта начального общего образования»

5. Приказ № 6 от 15 января 2020 г. «Об утверждении плана мероприятий по реализации Концепции преподавания учебного предмета «Основы безопасности жизнедеятельности» в образовательных организациях Российской Федерации, реализующих основные общеобразовательные программы, на 2020-2024 годы, утвержденной на заседании Коллегии Министерства просвещения Российской Федерации 24 декабря 2018 года». Опубликован: 06 марта 2020. https://docs.edu.gov.ru/document/41a489edc5d020

6. Федеральный государственный образовательный стандарт начального общего образования (утв. Приказом Министерства образования и науки Российской Федерации от 6 октября 2009 г. №373) [Электронный pecypc] URL: http://standart.edu.ru/catalog.aspx? Catalogld=959 (дата обращения: 10.10.2013)

\section{Чушина О.А.}

Иноязычная культура как средство формирования "homo moralis" (на примере неязыковых специальностей и направлений подготовки вуза)

Частное учреждение сочиального обслуживания "Детская деревня - SOS Вологда» (Россия, Вологда)

doi: $10.18411 / \mathrm{j}-06-2021-191$

\section{Аннотация}

В статье рассматривается понятие иноязычной культуры, критерии и показатели ее сформированности. Описан ценностный компонент модели процесса формирования иноязычной культуры студентов, который направлен на формирование homo moralis, человека духовного.

Ключевые слова: иноязычная культура, человек духовный, ценностный компонент модели, иностранный язык, неязыковые специальности вуза.

\section{Abstract}

The article deals with the concept of a foreign language culture. It presents criteria and indicators of its forming. The article describes the value component of the model of a foreign language culture forming, which is aimed at creating of homo moralis.

Keywords: foreign language culture, homo moralis, value component, foreign language, non-linguistic specialties of university.

Владение иностранным языком в современном мире является важным условием успешной самореализации личности. По мнению Л.В. Павловой, профессиональное образование, наряду с формированием профессионально-функциональной готовности 